\title{
CRÍTICA A LA MODERNIDAD Y DERECHOS HUMANOS DESDE LA FILOSOFÍA DE IGNACIO ELLACURÍA
}

\author{
Alejandro Rosillo Martínez ${ }^{1}$
}

\begin{abstract}
Resumen:
Se analiza un concepto clave de la Filosofía de la Liberación de Ignacio Ellacuría, a través del que realizar la crítica a la Modernidad: la civilización de la pobreza. Se proponen las consecuencias que esta crítica acarrea a la concepción y fundamentación de derechos humanos, y se propone comprenderlos, desde América Latina, como herramientas de luchas de liberación de las diversas subjetividades emergentes.
\end{abstract}

Palabras clave: Derechos humanos. Liberación. Pobreza. Capitalismo.Modernidad.

\section{CRITIQUE OF MODERNITY AND HUMAN RIGHTS FROM THE PHILOSOPHY OF IGNACIO ELLACURÍA}

\begin{abstract}
:
I analyze a main concept of the Philosophy of the Liberation of Ignacio Ellacuría, through which he carry out the critique of Modernity: the civilization of poverty. I establish the consequences that this criticism brings to the conception and foundation of human rights, and I propose to understand them, from Latin America, as tools of liberation struggles of the various emerging subjectivities.
\end{abstract}

Keywords:Human rights. Liberation. Poverty. Capitalism. Modernity.

\section{INTRODUCCIÓN}

Es un lugar común señalar que los derechos humanos, en sus presupuestos esenciales, son profundamente occidentales. Esto no quiere decir que otras culturas u otros pueblos no hayan desarrollado, independientemente de Occidente, nociones de dignidad humana y logrado estructurar procesos de lucha que favorezcan la satisfacción de sus necesidades y la producción y reproducción de su vida. A lo que nos referimos es a la noción estricta y formal de "derechos humanos" en relación directa a tres fundamentos (Panikkar, 1982): la universalidad, el individualismo y la democracia liberal. En cuanto al primer punto, se afirma la existencia de una naturaleza humana universal que es cognoscible a través de la razón, o si no se aceptan las posturas iusnaturalistas, se afirmaría un racionalismo que funda una "ética pública" que tendría propósitos universalistas al considerar que los valores

Profesor investigador de la Facultad de Derecho de la Universidad Autónoma de San Luis Potosí. Coordinador académico de la Maestría en Derechos Humanos de la UASLP. Correo electrónico: alejandro.rosillo@uaslp.mx 
postulados por ella son los únicos válidos para estructurar una sociedad respetuosa de la dignidad humana. En segundo lugar, esta noción se fundamentaría en la defensa del individuo frente al estado y a la sociedad, y se relacionaría con la noción de "derechos subjetivos" exigibles al poder público. Por último, la democracia liberal sería el sistema político donde se desarrollan los derechos humanos. Se trataría de la estructuración del estado moderno en conexión con el individualismo, lo que conlleva a una atomización de la sociedad; es decir, cada individuo exige sus derechos y cumple sus obligaciones ante el estado, y no existe vínculo alguno con los demás individuos (según el contractualismo clásico, el vínculo entre individuos existiría sólo antes de realizar el "contrato social", y después de aceptarlo la relación se establecería hacia el estado). Así, los límites de la libertad del individuo son los límites de las libertades de los otros individuos, lo cual justificaría racionalmente que la decisión de las mayorías sea lo que legitime las acciones del estado. Se trataría de la institucionalización y normalización de derechos humanos.

Ahora bien, como lo hemos afirmado en otros escritos (Rosillo, 2015; Rosillo et al., 2018), la Filosofía de la Liberación (FL) considera que los derechos humanos son algo valioso y necesario para la estructuración de una sociedad justa, pero deben desprenderse de su concepción abstracta, idealizada y simplificadora. Lo que verificamos en la época actual es que este uso ideologizado se ha vuelto cada vez más común; de ahí la importancia de los planteamientos de la FL. En efecto, mientras los países de Occidente -0 mejor dicho, sus gobiernos y grupos de poder- se congratulan del respeto de los derechos humanos dentro de sus territorios y critican a otras culturas por no asumir sus valores e imitar sus estructuras sociales, poco se cuestionan respecto a la manera en que han ido conformando a la "sociedad mundial" o al "sistema-mundo". Parecería que a pesar de la pretensión de universalidad que el propio Occidente ha enarbolado respecto a los derechos humanos, su visión no es realmente "mundial" sino meramente nacional o, a lo más, desigualmente inter-nacional. Al igual que la Modernidad hegemónica ha querido negar la complejidad de derechos humanos (Rosillo et al., 2018, pp. 353-384), la globalización neoliberal actual desea simplificar el mundo, como bien describe Hinkelammert (2003, p. 101):

Toda la estrategia de globalización del mundo ha desembocado en esta lucha contra la complejidad del mundo. Efectivamente, para que las soluciones sean simplistas, el mundo tiene que serlo también. Todo el sistema ahora se hace agresivo frente a un mundo complejo. La complejidad de las relaciones entre los seres humanos, la complejidad de la naturaleza, la complejidad de las culturas: todas estas complejidades faltan ahora eliminar para cumplir con la ilusión de que el simplismo un día pueda funcionar. Hay una fórmula para este proceso: la eliminación de las

\begin{tabular}{|l|l|l|l|c|}
\hline Q & Anoista & Agosto - Dezembro 2018 & p. $4-26$ \\
\hline
\end{tabular}


distorsiones del mercado, la cual resume bien lo que es el fundamentalismo de mercado. Estas distorsiones resultan de la complejidad del mundo.

La Modernidad ha limitado el análisis del cumplimiento de los derechos humanos dentro de los Estados-nación, soslayando todo el entramado mundial que compone a la sociedad actual, al grado de constituirla en un sistema-mundo. Esta dimensión universal se expresaría por medio de los compromisos internacionales que asume cada estado, aunque su cumplimiento o incumplimiento se continúa analizando como algo propio de cada estado en relación con su población y dentro de su territorio. Por ejemplo, al Occidente democrático le cuesta percatarse de lo poco democráticas que son las institucionales internacionales que ha promovido, o de sus actitudes imperialistas y neocoloniales con el Tercer Mundo. Razón lleva Antonio González (1998, p. IV) cuando señala que "las democracias nacionales son dictaduras internacionales" al referirse a la actual configuración mundial. Pero estas dictaduras internacionales no sólo se ubican en el plano de las instituciones mundiales (Fondo Monetario Internacional, Banco Mundial, etc.), sino también en el constante intervencionismo y violación a las soberanías populares. Enrique Dussel señala algo semejante, al criticar la razón cínica que ejerce Occidente:

\begin{abstract}
...aunque se declara ser un poder 'democrático' con respecto a su propio pueblo (ad intra), sin embargo su cinismo con respecto al Otro, a la Alteridad, al resto externo de la humanidad (ad extra), impide el ejercicio honesto y serio del Principio democrático con sentido normativo. ¿Cómo puede darse éticamente el reconocimiento de la igualdad humana a todos los miembros de la propia comunidad política, cuando se le atribuye a esa misma comunidad el derecho de declarar 'inhumano' al resto de la humanidad? ¿Cómo puede un demócrata, que conciba la democracia no meramente como un procedimiento político etnocéntrico sino al mismo tiempo con exigencias normativas, ser despótico con los Otros, con los débiles, con los vencidos, con los postcoloniales...? El que mata a los otros insensiblemente termina por suicidarse en el 'sin-sentido' de un orden inmoral (Dussel, 2007, p. 288).
\end{abstract}

Así podemos detectar en el pensamiento oficial de Occidente tanto un uso ideologizado de los derechos humanos como una ausencia de una auténtica perspectiva mundial-global al respecto. En otros artículos, hemos mostrado la manera en que Ignacio Ellacuría ${ }^{2}$ hace la crítica al concepto formal de derechos humanos usando el método de

2 Ignacio Ellacuría (1930-1989) nació en Portugalete, Vizcaya, España. En 1947 entró en el noviciado jesuita en la ciudad de Loyola. Estudió Humanidades y Filosofía en Ecuador, en la Universidad Católica de Quito. Estudio teología en Innsbruck, y ahí en 1961 fue ordenado sacerdote en Innsbruck. Se doctora de Filosofía en la Universidad Complutense de Madrid con una tesis sobre el pensamiento zubiriano. En 1967 se instala en El Salvador para colaborar en la UCA, de la que llega a ser rector. En 1975 obtiene la nacionalidad salvadoreña. Es asesor de Monseñor Óscar Arnulfo Romero. Se constituyó en una voz importante en el

\begin{tabular}{|l|c|c|c|c|}
\hline Ronita Dialectus & Ano 5 & n. 13 & Agosto - Dezembro 2018 & p. 4-26 \\
\hline
\end{tabular}


historización (Rosillo, 2004), ahora abordaremos un aspecto más radical de su pensamiento: la crítica de la Modernidad. Como bien señala el profesor Tamayo, la filosofía y la teología de Ellacuría plantean al pensamiento filosófico y teológico del Primer Mundo la necesidad de un cambio de dirección, de un giro copernicano. (Tamayo, 2007)

Esta crítica de Ellacuría de la Modernidad ${ }^{3}$, que cuestiona al Primer Mundo y lo impele a un "giro copernicano", ¿cómo afecta a los derechos humanos? ¿Habría que dejarlos a un lado y buscar otro discurso? ¿O pueden ser repensados y asumidos más allá de la Modernidad? La FL valora la idea de los derechos humanos, pero no los sacraliza ni los asume de forma ingenua ni simplista; desde el pensamiento de la liberación pueden repensarse los derechos humanos y lograrlos insertar dentro de la praxis de liberación de los pueblos oprimidos y excluidos.

\section{LA CRÍTICA DE IGNACIO ELLACURÍA A LA MODERNIDAD}

Ellacuría realiza importantes críticas a la Modernidad a partir de una de sus propuestas más radicales: la construcción de una "civilización de la pobreza". Uno de los textos donde encontramos de forma significativa esta crítica es el siguiente:

\footnotetext{
Sin querer hablar de antimodernidad, por lo que el término pudiera suponer de vuelta al pasado o de desconocimiento de valores fundamentales de la modernidad, es menester fijarse en que la mayor parte de la humanidad no está cansada o hastiada de la modernidad, sino que está indignada con ella. Esto significa una llamada a empezar de nuevo con la vista puesta en los desheredados de la historia, en las víctimas de la civilización de la riqueza. (Ellacuría, 2000a, p. 353)
}

En diversos escritos, Ellacuría insiste en la construcción de un orden histórico nuevo, un mundo nuevo, lo que nos aclara el sentido de su crítica:

Pero sí quiero, por lo que importa para construir un mundo nuevo, desenmascarar la
hipocresía fundamental de querer lograr la democracia por medio de la violación del
derecho, de los derechos humanos y del derecho internacional; de querer promover
el bien de los pueblos poniendo siempre por delante los intereses mezquinos de la
propia seguridad y aun de la capacidad de dominación; de querer buscar el
desarrollo económico de los otros principalmente en función de multiplicar las
ganancias propias; de propugnar la libertad de unos pocos sin importar nada la

proceso de negociación entre las guerrillas y el gobierno salvadoreño durante la década de 1980. El 16 de noviembre de 1989 es asesinado, junto con seis compañeros jesuitas, una trabajadora y su hija, por un batallón del ejército salvadoreño.

3 En el mismo sentido podemos encontrar elementos críticos del pensamiento de Hinkelammert y de Dussel. Aunque nos centraremos en el desarrollo de Ellacuría sobre la "civilización de la pobreza" y haremos menciones análogas y complementarias del pensamiento de los otros dos filósofos de la liberación.

\begin{tabular}{|l|c|c|c|c|}
\hline Qevista Dialectus & Ano 5 & n. 13 & Agosto - Dezembro 2018 & p. 4-26 \\
\hline
\end{tabular}


muerte terrorista de muchos y la necesidad de que la justicia regule las posibilidades reales de la libertad. (Ellacuría, 2000a, p. 350)

La Modernidad condujo a la formación de una civilización basada en la riqueza, lo que es, para Ellacuría, la raíz originaria de los males del mundo presente. "Riqueza" como un concepto y una realidad complejos, de suma importancia en la Modernidad, por el cual se divide al planeta en "mundo rico" y "mundo pobre", y de la misma manera a los sectores de una sociedad. Esta civilización está construida sobre la necesidad de acumular; se piensa que la acumulación de riqueza es el único medio para tener seguridad, libertad, dominio sobre los demás, poder, estima, placer y desarrollo cultural. Ellacuría denuncia como un dinamismo del mal común el "el afán de riqueza y la degradación consumista, que es propugnada por la abundancia excesiva" (Ellacuría, 2000b, p. 645). No se trata sólo de una decisión personal o colectiva, sino que es estructural debido a la dinámica del capital que se ha convertido en la fuerza dominante del mundo.

Un auténtico análisis de la realidad de la humanidad debe realizarse en términos mundiales o globales. Esto es posible por el hecho de que los seres humanos constituyen físicamente una especie, un phylumbiológico, y esta corporeidad universal es el fundamento de la sociedad mundial. Señala Ellacuría que "[1]a corporeidad universal significa mediatamente aquella primaria condición material en la cual coinciden todos los hombres y que los unifica con el resto del universo o, al menos, con el resto de la realidad material de nuestro universo; es una característica por la cual los distintos tiempos humanos tendrán siempre una primaria unidad por estar inmersos en la misma unidad material del cosmos. Pero la corporeidad significa más inmediatamente aquel carácter de corporeidad que el compete al hombre por construir físicamente una especie" (Ellacuría, 1999a, pp. 447-448). La humanidad, a través de diversos procesos históricos, ha ido unificándose hasta llegar a unapluriversalidad histórica del presente, que coloca a los individuos y grupos humanos en una línea estricta de coetaneidad y no sólo de contemporaneidad. No se trata de una visión ilustrada, que piensa que la universalidad en la historia es producto de la inscripción de todos los pueblos y culturas en una misma línea temporal donde se puede tener un mayor o menor desarrollo, en la que lleva la delantera las naciones occidentales:

Es esta unidad la que permite hablar de tiempos plurales propiamente tales: la unidad de la especie es pluralizada procesualmente y va adquiriendo distintas alturas y edades diversas. La corporeidad universal con sus procesos diversos permite y exige hablar de tiempos plurales, pero no es suficiente para hablar de un único

\begin{tabular}{|l|l|l|l|l|}
\hline Qevista Dialectus & Ano 5 & n. 13 & Agosto - Dezembro 2018 & p. 4-26 \\
\hline
\end{tabular}


tiempo histórico, que sea verdaderamente uno y que dé paso a una misma historia (Ellacuría, 1999a, pp. 447-448).

Como ha señalado Antonio González, en referencia a Zubiri y Ellacuría, el ámbito de la alteridad humana es primordialmente el ámbito del sentir humano, previo a los diversos sentidos o los distintos lenguajes (González, 1994). Por lo tanto, los comportamientos humanos pueden constituir una unidad sistémica en virtud de que unos están estructuralmente determinados por los otros. De ahí que, desde la FL, se proponga una pluriversalidadglobal es decir, que sea capaz de incluir la heterogeneidad de sentidos-que confronta a la universalidad eurocéntica. ${ }^{4}$

Desde dicha perspectiva global, Ellacuría analiza el mal presente en la realidad histórica, el cual es patente en el actual orden mundial. Es un orden que deshumaniza al ser humano, al tener en una situación de subdesarrollo y de dependencia a pueblos enteros, y que tiene sus raíces en la colonización llevada por Europa a partir del siglo XVI y que perdura hasta la actualidad a través de diversos mecanismos y procesos de la colonialidad del poder (Quijano, 2000). Esto conduce a Ellacuría a constatar "que nunca hubo en la historia del mundo tantos hombres tan pobres, tan desposeídos, sobre todo con tan pocos ricos y depredadores" (Ellacuría, 1999b, p. 201). No rechaza los adelantos científicos y tecnológicos, ni los logros morales de la Modernidad, pero es consciente del desarrollo capitalista que ha acompañado este progreso y cuestiona los poderes que ha generado y su capacidad auténtica de humanización:

\begin{abstract}
Mirada la realidad histórica en su conjunto, es imposible negar que se han acrecentado los poderes de la humanidad: la humanidad de hoy es más poderosa y está más capacitada de lo que estaba la humanidad de hace veinte siglos; en este sentido el cambio ha sido sobrecogedor. Pero esto no anula ciertas sospechas: ¿son los poderes desarrollados los verdaderos poderes que necesita la humanidad para humanizarse? ¿No se habrán desarrollado unos poderes con mengua y aun con aniquilación de otros poderes más importantes? ¿Está asegurado que los poderes actuales no dejen un día de serlo? ¿No ha habido en las historias particulares de los pueblos rutas falsas en el acrecentamiento de su poder que lo han llevado a su destrucción o, al menos, a su empobrecimiento? (Ellacuría, 1999a, p. 563)
\end{abstract}

Entonces señala como puntos destacables de este mal mundial los siguientes (Ellacuría, 1989):

4 Immanuel Wallerstein (2007, pp. 13-14) analiza el universalismo europeo, y los liga con los conceptos de derechos humanos, democracia y superioridad moral de la civilización occidental, señala que "[c]omprender cómo es que estas ideas se expresaron originalmente, por quién y con qué objeto, es una parte indispensable en esta tarea de evaluación"; salta a la vista la coincidencia con Ignacio Ellacuría y su método de historización de los conceptos.

\begin{tabular}{|l|l|l|l|l|}
\hline Rovista 2 Alalectus & Ano 5 & n. 13 & Agosto - Dezembro 2018 & p. $4-26$ \\
\hline
\end{tabular}


a) La ampliación de la brecha entre ricos y pobres, ya sean regiones, países o grupos humanos, lo cual implica que la distancia es cada vez mayor y que cada vez sea más grande el número de pobres -al crecimiento aritmético de los ricos corresponde un crecimiento geométrico de los pobres-;

b) El endurecimiento de los procesos de explotación y de opresión con formas, eso sí, más sofisticadas;

c) La destrucción ecológica progresiva de la totalidad del planeta.

d) Y, en especial, la deshumanización palpable de quienes prefieren abandonar la dura tarea de ir haciendo su ser con el agitado y atosigante productivismo del tener, de la acumulación de la riqueza, del poder, del honor y de la más cambiante gama de bienes consumibles.

Después de más de tres décadas de estos señalamientos, se podrían citar ejemplos y estadísticas -que no hacemos por no desviarnos del tema- que demuestran la actualidad de este análisis en sus términos generales. Habría que considerar algunas nuevas dinámicas que componen la negación de humanidades; como han mostrado autores contemporáneos, una nota destacable de la estructura mundial actual es ya no sólo la existencia de grandes sectores explotados, sino algo todavía más deshumanizante: la exclusión (Bauman, 2005). ${ }^{5} \mathrm{El}$ drama

5 Ellacuría ya señalaba: "Hay mayorías campesinas e indígenas explotadas, y a veces, ni siquiera explotadas, sino completamente marginadas de la historia" (Ellacuría, 2000c, p. 26). Por poner otro ejemplo, Boaventura de Sosa Santos analiza el surgimiento del fascismo social, que no se trata de un régimen político sino de uno social y civilizacional. El Estado queda como un testigo complaciente en algunas ocasiones, $\mathrm{y}$ como un culpable activo en otras. La democracia es reducida a formalidades y entonces los estados democráticos son capaces de convivir con sociedades fascistas. Son clases de exclusión social que existen tanto dentro de las sociedades como en las relaciones entre países. En este contexto, distingue el sociólogo portugués cuatro clases de fascismo: a) El fascismo del apartheid social: Es la segregación social de los excluidos a través de la división de ciudades en zonas salvajes y zonas civilizadas. Éstas se convierten en "castillos neofeudales" como expresión de la nueva segregación urbana: urbanizaciones privadas cerradas, comunidades encercadas, etc. En las zonas civilizadas el estado actúa democráticamente y protegiendo los derechos humanos, mientras que en la zonas salvajes, el estado actúa de manera fascista, sin ningún respeto por el derecho ni los derechos fundamentales; b) el fascismo paraestatal: Es cuando actores sociales muy poderosos, con complicidad del estado, usurpan prerrogativas de éste -como la coerción y la regulación social-, o bien las neutralizan. Este fascismo tiene dos dimensiones: el fascismo contractual y el territorial. El primer se da cuando las discrepancias de poder entre las partes en el contrato civil es tal que la más débil y vulnerables acepta las condiciones impuestas por la parte más fuerte, por muy costosas y despóticas que sean. El fascismo territorial, por su parte, tiene lugar siempre que los actores sociales con enormes capitales disputan al estado el control sobre los territorios donde actúan, o neturalizan ese control al cooptar y coaccionar a las instituciones estatales y ejercer la regulación social sin que los ciudadanos involucrados participen; c) el fascismo de la inseguridad: Es la manipulación discrecional del sentido de la inseguridad de las personas y grupos vulnerables debido a la precariedad del trabajo o a casusa de accidentes o eventos desestabilizadores. d) El fascismo financiero: Controla los mercados financieros y su "economía de casino"; es un fascismo pluralista en el sentido de que los flujos de capital son el resultado de las decisiones de inversores individuales o institucionales esparcidos por todo el mundo y que no tienen nada en común, tan sólo el deseo de maximizar sus activos. Conlleva un espacio-tiempo virtualmente instantáneo y global, que le

\begin{tabular}{|c|c|c|c|c|}
\hline Q Ronista Qialectus & Ano 5 & n. 13 & Agosto - Dezembro 2018 & p. $4-26$ \\
\hline
\end{tabular}


traído por el actual sistema global capitalista podría sintetizarse a través de una afirmación por lo demás cínica: más vale ser explotado que ser excluido. La Modernidad no sólo produce desperdicios materiales a través de sus altas tasas de consumismo, también coloca en esa calidad de desecho a grandes capas de la población mundial. A este orden global, Ellacuría lo nombra como civilización de la riqueza, la cual contradice un principio básico de humanidad: la prioridad del trabajo sobre el capital; y un principio básico de la fe cristiana: la prioridad de los muchos pobres sobre los pocos ricos (Ellacuría, 1993a, p. 396).

La civilización de la riqueza incluye la alienación, concepto que ha sido desarrollado por otros autores de la FL. Para Dussel, totalizar la exterioridad, sistematizar la alteridad, negar al otro como otro es la alienación. Alienar es vender a alguien o algo; es hacerlo pasar a otro posesor o propietario. La alienación de un pueblo o individuo singular es hacerle perder su ser al incorporarlo como momento, aspecto o instrumento del ser de otro. La alienación acompaña diversas prácticas de la Modernidad, de esa "civilización de la riqueza" que menciona Ellacuría; señala Dussel:

\footnotetext{
Es aquí donde la prudentia o sabiduría del recto obrar se transforma en la "razón"; el arte de prever y ganar la guerra. La justicia no es sino la habilidad de dar al poderoso lo arrebatado al débil bajo apariencia legal. La templanza no es sino el confort que llega a forjar una sensibilidad pétrea, impermeable, a toda miseria ajena. Y así, el lícito confort de la sociedad de consumo no descubre que su encubierta gula es hambre en el dominado; la prepotencia del empresario es indignidad en el asalariado; la relación sexual pagada es degeneración de la prostituida; la dominación pedagógica del padre es fracaso del hijo... (Dussel, 1996, p. 74)
}

Si somos conscientes de que "derechos humanos" es el discurso político más importante de la Modernidad, debido a su carga legitimadora y "normalizadora", los cuestionamientos de Ellacuría a la civilización de la riqueza deben conducirnos a replantearnos sus fundamentos. La concepción de la ciudadanía en el estado moderno, estructurado en función de la nacionalidad y la territorialidad, reduce el reconocimiento de dignidad a los seres humanos, justificando la desigualdad entre el disfrute de derechos. Así, la satisfacción o insatisfacción de derechos humanos se analiza tan sólo como un asunto propio de cada nación, ya sea por su estado o dentro de su territorio; se invisibilizan todas las tramas de poder en el ámbito internacional que influyen en la violación de la dignidad humana dentro de los territorios nacionales o sólo se muestran aquellas acciones que, sobre todo venidas de los países ricos, se presentan a sí mismas como promotoras de derechos humanos, desarrollo y

da un poder discrecional. Se ha convertido en el modelo y el criterio operativo de las instituciones de regulación global (Santos, 2009, pp. 560 y ss.).

\begin{tabular}{|c|c|c|c|c|}
\hline Revista Alatectus & Ano 5 & n. 13 & Agosto - Dezembro 2018 & p. $4-26$ \\
\hline
\end{tabular}


democracia. En efecto, por lo menos nos encontramos de nuevo, aunque desde otra perspectiva, ante dos cuestiones que deben ser replanteadas: No se puede seguir sosteniendo al individuo abstracto como sujeto de los derechos humanos, y el discurso sobre su universalidad debe cuestionarse desde el-lugar-que-da-verdad ${ }^{6}$ para superar el eurocentrismo.

La afirmación del individuo fue un elemento indispensable para la lucha contra el “Antiguo Régimen” y la opresión que realizaba contra ciertos grupos, pero no tardó en ser funcional a la expansión del capitalismo. El "origen oficial" de los derechos humanos, en especial su pretensión de universalidad, surge al mismo tiempo que los intereses de los burgueses que comenzaban a construir una nueva racionalidad económica basada en la acumulación de capital. ${ }^{7}$ En este sentido, nos encontramos en una situación donde una gran parte de la humanidad estructura un estilo de vida donde el individualismo es una característica fundamental. Pero se trata de un individualismo destructor, como lo ha señalado Albert Nolan: "El individualismo no es un fenómeno nuevo. Lo nuevo - y éste es uno de los signos importantes de nuestro tiempo - es la conciencia creciente de que el individualismo narcisista es psicológica, social, política, económica, espiritual y ecológicamente destructivo" (Nolan, 2007, p. 42). Lo cual también constata Ellacuría al señalar la insolidaridad del individuo: “(...) modos abusivos y/o superficiales y alienantes de buscar la propia seguridad y felicidad por la vía de la acumulación privada, del consumismo y del entretenimiento; sometimiento a las leyes del mercado consumista, promovido propagandísticamente, en todo tipo de actividades, incluso en el terreno cultural; insolidaridad manifiesta del individuo, de la familia, del Estado en contra de otros individuos, familias o Estados" (Ellacuría, 1993a, p. 405). Además, la libertad en la civilización de la riqueza es una libertad falsa, pues el ser humano se ve sometido a una doble alienación: “[L]a de someter la propia libertad a los dinamismos necesitantes y cosificantes del dinero y la de someter la propia identidad a un modelo creado no para la liberación sino para la sumisión” (Ellacuría, 1993a, p. 421).

6 Expresión de Ignacio Ellacuría para referirse a una epistemología situada, a un logos histórico: "El momento opcional, que busca ese lugar-que-da-verdad y que hace verdad, no debe ser ciego, sino iluminado, en un primer paso, por una valoración ética que hace de la justicia y de la libertad, mejor dicho de la no-justicia y de la no-libertad que se dan en nuestra situación como hechos primarios, un punto de referencia esencial, e iluminado, en un segundo paso, por la valoración teórica que se ve en la injusticia y en la no-libertad una de las represiones fundamentales de la verdad, 'la injusticia que reprime la verdad"' (Ellacuría, 1993b, p. 115).

$7 \mathrm{Su}$ contenido inicial muestra con claridad que los sujetos beneficiados eran hombres concretos, con ciertos bienes que les posibilitaban ejercer las facultades que predicaban como universales: libertad contractual, libertad religiosa, propiedad privada de uno mismo y de los medios de producción, el derecho de movimiento (ius communications) y el derecho a comerciar todo lo que uno se encuentre (ius comercii). ¿Eran universales estos derechos o sólo se predicaban de esta manera para justificar el expansionismo del naciente capitalismo?

\begin{tabular}{|c|c|c|c|c|}
\hline Rovista Dialectus & Ano 5 & n. 13 & Agosto - Dezembro 2018 & p. $4-26$ \\
\hline
\end{tabular}


Por otro lado, si bien podemos considerar que los movimientos burgueses del siglo XVIII y su discurso universalista fueron en un inicio emancipadores a través de la afirmación de nuevos derechos, no obstante, una vez satisfechas sus necesidades y establecidas las instituciones necesarias para asegurar el poder (Ellacuría, 2000d, p. 647), su discurso comenzó a utilizarse para impedir el surgimiento de nuevas subjetividades, hasta que se dieron las diversas revoluciones obreras y socialistas que a su vez lograron la afirmación de sus derechos. En otras palabras, los derechos humanos comenzaron siendo instrumentos-y no fines como lo ha generado suinversión ideológica (Rosillo, 2016)- para la defensa contra el abuso y las injusticias ocasionadas por las monarquías absolutas, en un primer momento y, después, por la revolución industrial. Con el tiempo, especialmente después de la segunda guerra mundial, esta función se ha seguido manteniendo pero ha quedado en un lugar secundario en relación a una nueva: la de constituirse internacionalmente -y con pretensiones mundiales- en el referente único y considerado como el mejor para la articulación y la organización de vida en sociedad. De ahí que, en el imaginario social de Occidente, la política corra el riesgo de quedar reducida a afirmar el dilema "derechos humanos o barbarie" o, en términos más extremos, a la invitación al "choque de civilizaciones". Es decir, la inversión ideológica de derechos humanos es producto, a la vez, de la civilización de la riqueza que Ellacuría denuncia.

Pero, yendo más allá, el discurso universalista como instrumento de dominación se hace presente desde el siglo XVI con el inicio de la expansión europea, siendo uno de sus personajes más representativos Ginés de Sepúlveda (Rosillo, 2012). Entoncesse usaba un lenguaje religioso y se justificaba la conquista $-\mathrm{y}$ la explotación de tierras y recursos naturales- en función de llevar a los indígenas a la verdadera religión. En los siglos posteriores, el lenguaje se volvió más secular, y se justificaba el colonialismo en razón de la superioridad moral de la civilización occidental. No sólo el pensamiento de John Locke y su cumplimiento de la ley de la naturaleza (y la razón) son un buen ejemplo de esto, también el pensamiento de Hegel y su concepción del desarrollo del Espíritu absoluto. Es decir, si bien encontramos diferencias entre el llamado a la "universalidad" del siglo XVI con el de los siglos posteriores, ambos fueron funcionales para la generación de la colonialidad del poder. Aunque durante el siglo XX las colonias europeas aún existentes lograron su independencia, el lenguaje de dicho universalismo se modificó para continuar con los fines de explotación. En efecto, el llamado actual de "universalidad" se da principalmente a través de tres modalidades (Wallerstein, 2007, p. 12):

\begin{tabular}{|l|l|l|l|l|}
\hline Qenista Dialectus & Ano 5 & n. 13 & Agosto - Dezembro 2018 & p. 4-26 \\
\hline
\end{tabular}


a) El argumento que sostiene que las prácticas políticas de los líderes de las potencias occidentales son para impulsar la "democracia" y defender las "libertades".

b) El discurso sobre "el choque de civilizaciones" donde se supone que la civilización occidental es superior a las otras civilizaciones, pues es la única que ha logrado basarse en valores y verdades universales.

c) La defensa de las "verdades científicas" del mercado que obliga a los gobiernos -en especial a los del Tercer Mundo- a aceptar las leyes de la economía neoliberal.

Cuando Ellacuría analiza la civilización de la riqueza cuestiona en cierta forma este tipo de universalismo. Si bien su pensamiento tiene influencias zubirianas y marxistas, al iniciar su cuestionamiento de la civilización de la riqueza hace uso de uno de los autores modernos más representativos: Immanuel Kant. ${ }^{8} \mathrm{Al}$ recordar el imperativo ético del filósofo de Könisberg, sostiene que el modelo propuesto por la civilización de la riqueza no es universalizable y, por lo tanto, no es moral. ${ }^{9}$ Esta universalización no es posible por razones ambientales, pues si toda la humanidad consumiera la energía que requiere el estilo de vida occidental, simplemente el planeta no lo resistiría, y no es deseable por la falsa felicidad que otorga al ser humano y, sobre todo, porque es un modelo de vida que necesita de la explotación de otros:

$[\mathrm{H}] \mathrm{a}$ de afirmarse contundentemente, primero, que la maldad impuesta de ese 'vivir
mal', de ese vivir 'muriendo' en lugar de vivir 'viviendo', se impone por sí misma y,
sobre todo, en relación con quienes dicen vivir bien, últimamente a costa de quienes
viven mal. Ha de afirmarse, en segundo lugar, que mientras, en el mejor de los
casos, el número de bien vivientes se multiplica aritméticamente, el de los mal
vividos se multiplica exponencialmente. (Ellacuría, 2000e, pp. 348-349)

8 Aquí se muestra lo analógico que puede tener la idea de universalidad. Por un lado están los discursos políticos universalistas - como los que dicta Wallerstein- que en realidad es la imposición del poder, son unívocos; pero también está el universalismo filosófico o moral, como es el de Kant, que identifica, grosso modo moralidad con posibilidad de universalización, si entendemos la universalidad como analógica.

9 Ellacuría utiliza este argumento de Kant contra la propia Modernidad, para demostrar su cinismo e hipocresía actual. Algo semejante descubre Dussel cuando ve en el pensamiento kantiano algún fundamento para la perversión de la legalidad funcionalista al colonialismo: "Para el buen moralista del centro que era Kant, la legalidad era la concordancia objetiva del acto con la ley, y su moralidad el querer cumplir la ley por deber. Si tomo como principio: 'Ama a la patria y lucha por ella', y enfrento un inglés del siglo XIX contra un nigeriano, ambos lucharán por su patria; ambos actos pueden elevar a su máxima como 'principio de una legislación universal'. Pero, da la casualidad que uno es perverso (el inglés) y otro éticamente heroico y ejemplar (el africano). Sin embargo, ambos actos son legales y morales para Kant. ¿Qué tipo de moral debió ser aquella, que pretendió medir desde las naciones y la cultura central las naciones periféricas y sus culturas, sino una moral imperialista? ¿Qué son los valores de un Scheler, y sus jerarquías, sino mediaciones de un proyecto occidental que los fundaba y que nunca apareció como tal en su Der FormalismusinderEthik? Las éticas de la ley, de la virtud, de los valores, del fin (sea telos, finis o constitución nacional kelseniana, es decir, teleológicas o positivas), son éticas encubridoras de su propio mundo y sistema." (Dussel, 2007, pp. 74-75). 
Así que la promesa de universalidad de Occidente hacia los países del Tercer Mundo es falsa y termina siendo un encubrimiento de la imposición global e imperial del capitalismo. $^{10}$

El análisis de la civilización de la riqueza nos lleva, desde el campo iusfilosófico, a afirmar que el ideal liberal de los derechos individuales, universales y abstractos garantizados por el estado liberal y democrático, está lejos de la realidad. Por eso, la fundamentación metafísica del "contrato social" que supone la existencia de un individuo sin concreción histórica, desde el cual se predican ciertos derechos, es insuficiente para defender la vida y la dignidad de los seres humanos. Ellacuría es claro al rechazar esta doctrina:

\begin{abstract}
Cuando Hobbes en 1651 escribía en Leviatán que son tres las causas de las luchas entre los hombres y que las tres están inscritas en la naturaleza humana: la inseguridad, la competencia y el deseo de gloria, estaba describiendo más la experiencia del hombre occidental emergente que algo necesariamente ínsito en la naturaleza humana. (Ellacuría, 1993a, p. 420)
\end{abstract}

Además, este "contrato social" también es peligroso por su idealismo utilizable fácilmente para los intereses del capitalismo; de ahí que, como hemos insistido, la FL rechace todo humanismo abstracto por ser fácilmente manipulable para la explotación de otros seres humanos: ningún ser humano puede ser usado como medio para conseguir que el ser humano en abstracto sea tomado como fin en sí mismo. (Ellacuría, 2001a, pp. 319-332)

Si mi libertad termina donde comienza la libertad del otro, entonces no hay obligación alguna respecto a las dificultades con las que se encuentra ese otro en el desarrollo de su vida; desaparece la alteridad que forma parte de la fundamentación de derechos humanos (Rosillo, 2015). Aparentemente, esta indiferencia ("respeto" a la libertad del otro) permite que el otro desarrolle su vida digna como mejor le parezca. Y esto se vincula con el temor de algunos teóricos liberales-individualistas a ideas de "bien común", "buena vida" o “justicia social”, bajo el argumento de considerarlos vehículos para el totalitarismo. Sin duda, esto puede tener algo de cierto como lo muestra el propio Ellacuría al hacer la crítica de la ideologización del "bien común" (Ellacuría, 2001b). No obstante, la crítica ellacuriana sigue

10 Ciertamente, Ellacuría hace su análisis influenciado por la "teoría de la dependencia", corriente de pensamiento generada contra el "desarrollismo" impuesto en América Latina en las décadas de los 1950 y 1960, desarrollada por sociólogos y economistas latinoamericanos como Fernando H. Cardoso, E. Falleto, T. Dos Santos, A. Gunder, entre otros, la cual puso en evidencia que el subdesarrollo no era una etapa previa y necesaria del desarrollo. El subdesarrollo de los países pobres, según esta teoría, es resultado de un proceso histórico, consecuencia del desarrollo de los países ricos. Si bien esta teoría ha recibido múltiples críticas, en muchos de sus análisis no ha sido superada y ha dado más de sí a partir de la nueva configuración mundial del capitalismo y sus recurrentes crisis a nivel global, y el ensanchamiento de la brecha entre países ricos y países pobres. (Biel, 2007)

\begin{tabular}{|l|l|l|l|l|}
\hline Rovista Dialectus & Ano 5 & n. 13 & Agosto - Dezembro 2018 & p. $4-26$ \\
\hline
\end{tabular}


viendo en el bien común una idea formal importante para buscar el acceso de las mayorías marginadas a los bienes necesarios para su vida. En cambio, el principio liberal en comento ha acarreado un totalitarismo del mercado, y del derecho a la propiedad privada sobre todos los demás derechos, llevando a que el individuo pacte el menor número de condiciones relacionadas con su compromiso social. En otras palabras, la liberalización pone el énfasis en el cumplimiento formal de los derechos (liberales) por encima de la manera en que el ser humano tiene acceso a los bienes para su vida digna. ${ }^{11}$ Influidos por el dogma de la mano invisible del mercado, para el neoliberalismo basta el respeto de la libertad del individuo para que cada miembro de la humanidad logre llevar una vida digna, sin hacer análisis alguno sobre el acceso a los bienes. Y esto significa, sin duda, un soslayo de la materialidad de la historia y de la dimensión ética-biológica del ser humano.

Por otro lado, el libre comercio, la desregulación de la economía y la proclama de la efíciencia de los mercados son los elementos más destacables de la actual razón universal capitalista, la cual ha instrumentalizado los derechos humanos, en especial aquellos generados por las luchas burguesas contra el "Antiguo Régimen”. Al respecto, señala Fariñas:

\footnotetext{
Y héte aquí, que esta nueva forma de homogeneización y de dominio universalista instrumentaliza a su favor el principio jurídico de la igualdad formal y el discurso de unos derechos humanos liberales e individuales, de carácter universal, rechazando, además, cualquier otro tipo de 'derechos' -como los que tienen un contenido social, redistributivo o igualitario-, que pudiera atentar contra la libertad del mercado. (Fariñas, 2006, p. 10)
}

Siguiendo la misma idea, podemos afirmar que el mercado acepta la existencia de derechos sociales, y hasta de garantías judiciales que los hagan exigibles, mientras el deudor no pretenda establecer políticas impositivas o distributivas que dañen "el buen funcionamiento del libre mercado". Y esto porque el individualismo que sustenta el pensamiento clásico de los derechos humanos, y su consecuente atomización de la sociedad, permiten colocar a las clases populares y a los sectores marginados -quienes son las que

11 Como ejemplo actual de esto, es paradigmático el caso que narra Vandana Shiva: "Cuando se celebró en Roma la Conferencia Mundial sobre Alimentación en 1996, la Organización de las Naciones Unidas para la Agricultura y la Alimentación (FAO) calculaba que el número de personas que padecía malnutrición había pasado de 450 millones en 1981, cuando se celebró el primer Día de la Alimentación, a 800 millones. Por lo tanto, la consagración del derecho a la alimentación debería ser la principal prioridad de cualquier política nacional e internacional. En lugar de hacerlo, en la Conferencia Mundial sobre Alimentación el secretario de Agricultura de Estados Unidos, Dan Glickman, anunció que ese país no podía reconocer el derecho a la alimentación, ya que violaba el derecho al comercio. A partir de entonces, el derecho a la alimentación se ha desmantelado a favor del derecho al comercio" (Shiva, 2006, p. 100).

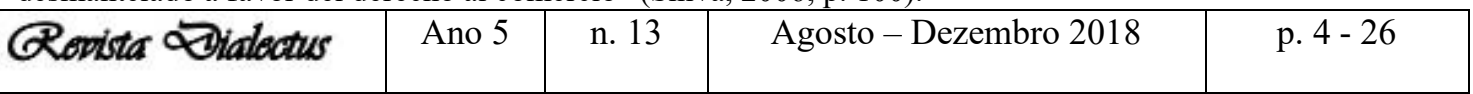


exigen derechos sociales, pues las clases pudientes no requieren ni se preocupan por su exigibilidad- ante un deudor insolvente: el estado.

Jon Sobrino, al comentar el análisis que realiza Ellacuría sobre la civilización de la riqueza, afirma que

esta civilización, en lo fundamental, está basada en y ofrece un espíritu que, en definitiva, lleva a la deshumanización. Es la civilización del individuo, del éxito, del egoísta buen vivir. Y el aire que respira el espíritu se enrarece todavía cuando el Occidente que la produce se comprende a sí mismo no sólo como logro de talante y nobles esfuerzos - en parte, muy reales, a los cuales se añade también una secular y gigantesca depredación histórica -, sino como fruto de una predestinación, como antaño se comprendían los pueblos elegidos según las religiones. (Sobrino, 2007, p. 29)

Como hemos visto, esta realidad pone en tela de juicio a derechos humanos como instrumentos políticos funcionales a esta civilización de la riqueza, tanto por su individualismo abstracto como por su discurso universalista. No obstante a su matriz moderna utilizada ideológicamente para legitimar a la civilización de la riqueza, para la FL los derechos humanos pueden ser repensados y ser instrumentos políticos a favor de los pueblos y personas explotados y excluidos; en los términos que venimos utilizando en esteartículo, los derechos humanos más que funcionales a la civilización de la riqueza, pueden serlo por la civilización de la pobreza.

\section{DERECHOS HUMANOS Y CIVILIZACIÓN DE LA POBREZA}

Bajo el capitalismo sólo pueden darse, y aleatoriamente, derechos humanos completos para algunos y derechos humanos fragmentados y parciales para otros. La lógica de la civilización de la riqueza produce cesantes, trabajo informal y subempleo, mano de obra no calificada y vulnerable, inestable, y por lo tanto, viola derechos humanos. Esto es así porque, como insiste Ellacuría, se sigue una lógica económica orientada al lucro y no de necesidades humanas. En efecto, para la FL, además de desarrollar un fundamento sólido, abierto y plural de derechos humanos, es necesario ponerlos en conexión con uno de los elementos más radicales del pensamiento de Ellacuría: la civilización de la pobreza. Leonardo Boff ha señalado:

Las relaciones del mercado son relaciones sociales que rigen la producción, la distribución y el consumo de bienes y servicios. Por el hecho de estar constituido por relaciones sociales, lo social, y no lo individual, debería ocupar la centralidad

\begin{tabular}{|l|l|l|l|c|}
\hline Qovista Dialectus & Ano 5 & n. 13 & Agosto - Dezembro 2018 & p. 4-26 \\
\hline
\end{tabular}


del mercado. Lo que debe guiar las prioridades y orientar la lógica de su realización histórica no son las demandas del propio mercado, casi siempre artificiales, buscando únicamente el lucro, sino las necesidades de la vida humana en su concretización, que es siempre material, personal, social, cultural y espiritual. (Boff, 2005, p. 56)

El contraste entre la civilización de la riqueza y la civilización de la pobreza, Ellacuría lo sintetiza de la siguiente manera:

\begin{abstract}
Si la civilización de la riqueza pone su centro en las demandas del capital y en la acumulación privada (nacional o personal) y hace de ello no sólo el motor de la historia, sino que deja en sus manos la dirección de la misma, la civilización de la pobreza pone, ciertamente, como condición básica la satisfacción segura y permanente de las necesidades básicas de todos los hombres, pero, logrado esto, hace del desarrollo libre de a persona y de los pueblos al fuerza motriz principal y la utopía orientadora del presente. (Ellacuría, 2000e, p. 352)
\end{abstract}

En otros textos, también habla de la civilización del trabajo en contraposición de la civilización de la riqueza. No busca una oposición entre trabajo y ocio, sino la afirmación de un trabajo que no sea regido ni exclusiva ni predominantemente por el dinamismo del capital y de la acumulación, sino por el dinamismo real del desarrollo de la persona y del respeto al medio del cual forma parte:

\footnotetext{
El trabajo, produzca o no valor, que últimamente se concreta en mercancía y capital, es ante todo, una necesidad personal y social del hombre para su desarrollo personal y equilibrio psicológico, así como para la producción de aquellos recursos y condiciones que permiten a todos los hombres y a todo el hombre realizar una vida liberada de necesidades y libre para realizar los respectivos proyectos vitales. (Ellacuría, 1989, p. 359)
}

La civilización de la pobreza no consiste en la pauperización universal, sino que se contrapone así una sociedad configurada por el dinamismo capital-riqueza para suscitar un dinamismo distinto. Por eso, se rechaza la acumulación del capital como motor de la historia y la posesión-disfrute de la riqueza como principio de humanización, y se hace de la satisfacción universal de las necesidades vitales el principio del desarrollo y del crecimiento de la solidaridad compartida el principio básico de humanización.

En síntesis, la civilización de la pobreza tiene como sentido básico la búsqueda de formas de vida -en plural- que hagan posible el acceso de bienes para que todos los seres humanos puedan tener una vida digna, y que estas formas sean compatibles con los límites

\begin{tabular}{|c|c|c|c|c|}
\hline Qevista Dialectus & Ano 5 & n. 13 & Agosto - Dezembro 2018 & p. $4-26$ \\
\hline
\end{tabular}


ecológicos del planeta. ${ }^{12} \mathrm{Y}$ es que el capitalismo actual impide la generación de otras formas de vida que pueden satisfacer dichas necesidades: "La carta, por ejemplo, del desarrollo y del consumo como motor fundamental del proceso histórico ha obturado, sin duda, otras posibilidades de vida, de momento, social y mundialmente irrecuperables. Porque, en definitiva, las capacidades no son tan solo capacidades intelectuales, sino también volitivas, emocionales, valorativas, etc.” (Ellacuría, 1999a, p. 551).

Ahora bien, la civilización de la pobreza nos posibilita comprender derechos humanos desde la praxis de los pobres, los excluidos y los oprimidos. Ya hemos dicho que los derechos humanos surgieron principalmente como un instrumento de defensa frente al poder político, con el objetivo de limitar sus posibles abusos e impedir que se reprodujeran los excesos que habían vivido durante el antiguo régimen. En ese momento, quienes luchaban eran individuos concretos, en su situación de burgueses, que buscaban condiciones para reproducir su vida. Entonces eran una subjetividad emergente que a través de la abstracción invisibilizaron el conflicto que dio origen a sus derechos y los pretendieron como producto de la naturaleza humana y no de la praxis. A partir de ahí, los derechos humanos han constituido, en su versión dominante, la peculiar ideología normativa del mundo moderno-burgués.

Sin embargo, es importante distinguir entre las dos funciones que de los derechos humanos mencionamos párrafos arriba; como señala Nicolau-Coll, "no es lo mismo utilizar los derechos humanos para defenderse de los abusos de las empresas transnacionales o de los Estados (dictatoriales o democráticos) en cualquier lugar del mundo, que utilizarlos para imponer un modelo social, político y económico dado, en este caso del occidente moderno" (Nicolau-Coll, 2006, p. 31). Habría que añadir que no sólo las grandes mayorías populares, o las minorías discriminadas, han de defenderse de las empresas transnacionales o del estado, sino de diversas formas de poder que atentan contra la dignidad humana al impedir la producción y reproducción de la vida. En otras palabras, como señala Ellacuría, los derechos humanos deben ser instrumentos para combatir todo tipo de violencia estructurale institucional:

La existencia de mayorías muy por debajo de los niveles que se requieren y son posibles en nuestra época, incluso aunque no hubiera represión positiva, es la prueba de la injusticia de la estructura y de la violencia institucional. La violencia

12 Ellacuría ya consideraba la urgencia del cuidado ecológico y visualizaba a la sociedad capitalista como ecocida, lo cual coloca a nuestro autor también en la línea de la ética del cuidado propuesta por Leonardo Boff.

\begin{tabular}{|c|c|c|c|c|}
\hline Revita Q Dialectus & Ano 5 & n. 13 & Agosto - Dezembro 2018 & p. $4-26$ \\
\hline
\end{tabular}


institucional es así la violencia originante y la violencia principal. (Ellacuría, 1993c, p. 662)

Los derechos humanos siempre existen en relación con la sociedad, y en función de una concreción del ser humano. Su comprensión desde la civilización de la riqueza sostiene la existencia de "derechos" del individuo con total independencia de sus relaciones sociales y de la forma en cómo estos se construyen, y además no interesa si dichos derechos se ven afectados si el individuo es indígena, empresario, obrero, blanco, negro, varón, mujer, etc. El contractualismo clásico termina neutralizando la capacidad creativa del ser humano; señala que los individuos tienen derechos que pueden exigir a las instituciones del estado, pero a cambio las personas pierden su capacidad de lucha por la dignidad y la construcción de estructuras para el acceso igualitario a los bienes que satisfagan sus necesidades. Renuncian a esta capacidad de lucha porque le entregan al estado el poder de construir dichas estructuras, que son edificadas en función de los intereses de los sectores hegemónicos de la nación o del mundo. Además, al darles a los derechos humanos un carácter eterno, racional, universal y natural, se invisibilizan las relaciones humanas conflictivas que dieron origen a la acumulación de ciertos derechos, en este caso, de los derechos llamados como de libertad negativa.

En cambio, los derechos humanos en la civilización de la pobreza tienen su matriz en la praxis de los pueblos en busca de justicia, de mejores condiciones de vida que les permitan producir y reproducir su vida. Como señala Sobrino, "para sanar una historia gravemente enferma se necesita, de alguna forma, el aporte de pobres y víctimas" (Sobrino, 2007, p. 61). ${ }^{13}$ En la situación mundial actual, si realmente queremos tomarnos en serio la justicia es imprescindible asumir la importancia que tiene la praxis de liberación en el surgimiento de "nuevos derechos", y pensarlos desde el-lugar-que-da-verdad, como nos lo propone Ellacuría. Sólo así, por ejemplo, se pueden entender los llamados derechos de "tercera generación" que declaran el derecho a la cultura propia. Es la emergencia de los pueblos discriminados, que denuncian una racionalidad que los ha denigrado y asesinado, pues la imposición cultural rebaja y mata. Es la emergencia de los otros que se les ha negado la capacidad y la apropiación de la posibilidad de ser ellos mismos. Guarda relación con esta postura el imperativo categórico propuesto por Joaquín Herrera desde su postura de los

13 Algo semejante afirma Ellacuría: "Mientras haya pobres, la liberación vendrá de los pobres. Cuando deje de haberlos, porque ha sido superado mundialmente el estado de satisfacción de las necesidades básicas y haya sido superada también la desigualdad injusta" (Ellacuría, 2000b, p. 645).

\begin{tabular}{|l|c|c|c|c|}
\hline Q Ponitalatus & Ano 5 & n. 13 & Agosto - Dezembro 2018 & p. $4-26$ \\
\hline
\end{tabular}


derechos humanos como productos culturales, que se dan en contextos específicos de división que condicionan negativa y desigualmente el acceso a los bienes para la satisfacción de las necesidades humanas:

\begin{abstract}
Actúa de tal modo que las consecuencias de tu "antagonismo" frente a los procesos de división social, sexual, étnica y territorial del hacer humano tiendan a la construcción positiva de condiciones reales y concretas que permitan a los seres humanos poder llevar adelante sus vida accediendo igualitariamente a los bienes necesarias para vivir una vida digna de ser vivida. (Herrera, 2005, pp. 80-81)
\end{abstract}

Una concepción de derechos humanos desde el Tercer Mundo, desde el Sur, necesita pasar del individualismo a nociones comunitarias del ser humano. Ellacuría considera que ni el liberalismo burgués ni el estatismo son capaces de comprender la dimensión comunitaria de la persona; en cambio, es necesario dar más peso a lo social que a lo político: "Entre el individualismo y el estatismo debe construirse un tipo fuerte de sociedad, que supere el desenfreno de aquél, y la imposición dominante de éste" (Ellacuría, 1993a, p. 432). ${ }^{14}$ En este sentido, combatir la violencia estructural debe ser uno de los objetivos de la participación en el campo público de las organizaciones sociales, y no sólo para conseguir el poder sino con el objetivo de reforzar a la sociedad (Ellacuría, 1993d, p. 721).

Derechos humanos no debe comprenderse sólo en función de una sociedad institucionalizada donde con orden se expresan los intereses -eso sí, sólo los intereses que se consideran "legítimos"-, sino como un espacio conflictivo donde subjetividades emergentes luchan por mejores condiciones de vida. De lo contrario, derechos humanos se convierten en un elemento ideológico que, si bien en su momento nacieron como producto de una subjetividad emergente, una vez que se hace del poder, impide que otros sujetos realicen procesos de lucha e intenta dar por terminada toda novedad histórica. En este contexto, Ellacuría interpreta desde los pobres y su praxis de liberación, un derecho humano clásico:

El derecho a la existencia de las organizaciones populares es un derecho fundamental, reconocido como tal universalmente y amparado por nuestra Constitución y por nuestros compromisos (...) No se trata sólo de un derecho general de los hombres a unirse y organizarse para lograr fines honestos, sino del

14 En otro texto, también muestra su insatisfacción por los regímenes comunistas existentes de la época: "El camino de llegar a la justicia por la libertad (liberalismo) ha tenido buenos resultados para los más fuertes, como individuos o como pueblos, en su determinado momento, pero ha dejado sin libertad (liberación) a la mayoría de la humanidad. El camino de llegar a la libertad por la justicia ha dejado también históricamente mucho que desear, en determinado países" (Ellacuría, 2000b, p. 647). Aunque, cabe resaltar, el mal común en América Latina, en su mayoría, no provenía - ni proviene- de totalitarismos comunistas sino de un capitalismo periférico y neocolonial.

\begin{tabular}{|c|c|c|c|c|}
\hline Revista Dialectus & Ano 5 & n. 13 & Agosto - Dezembro 2018 & p. $4-26$ \\
\hline
\end{tabular}


derecho mucho más urgente que tienen los desposeídos e injustamente oprimidos a hacer valer sus derechos más fundamentales, que de otra manera se ven permanente, estructural y coyunturalmente conculcados. (Ellacuría, 1993e, p. 737)

Es decir, para la FL ciertos derechos nacidos de la Modernidad deben contemplarse en la construcción de un nuevo espacio político que posibilite superar democracias de baja intensidad, procedimentalistas y formalistas, que en los países latinoamericanos son utilizadas para legitimar los intereses privatistas de las clases sociales altas y de las empresas transnacionales, para dar paso a democracias donde se reconozcan nuevos derechos desde las luchas sociales que reivindican necesidades humanas:

\footnotetext{
"Las organizaciones populares tienen notables valores como dinamizadoras del proceso político y social. Superan, de hecho, el planteamiento de los partidos políticos, pues su actividad no se centra ni menos se reduce a una actividad electoral, sino que muestran una dedicación permanente como representación de los intereses populares (...). Han elevado, en definitiva, al pueblo oprimido de su condición de objeto a la de sujeto de su propio destino, de su condición de marginado a agente activo del proceso histórico". (Ellacuría, 1993e, p. 739)
}

Por eso, es incorrecto ver en la lucha por la transformación de las estructuras sociales, una reivindicación exclusiva de los derechos sociales y un desprecio por los otros tipos de derechos. Los llamados derechos de libertad y participación pueden ser medios para satisfacer necesidades tan importantes como los derechos económicos, sociales y culturales, y además pueden ser complementarios; lo importante es su historización, es decir, verificar el para qué se usan y el por quién se utilizan. Se trata de asumir el discurso de los derechos humanos y darles un uso alternativo a favor de los pobres. Por ejemplo, Ellacuría consideraba un crimen contra la democracia salvadoreña la no legalización de las organizaciones campesinas, a las que el gobierno calificaba de comunistas, desestabilizadoras y terroristas, no sólo por tratarse de una violación al derecho constitucional de organización y de libertad de asociación, sino porque consideraba que la organización campesina era una respuesta histórica a la violencia institucionalizada. Al contrario de lo que afirmaba el estado, la participación popular significaba una de las salidas fundamentales de la violencia estructural e institucionalizada que azotaban al país. ${ }^{15}$

15 "La legalización de las organizaciones populares campesinas encauzaría democráticamente la lucha de los trabajadores del campo. Si el país quiere avanzar en la línea de un mayor respeto de los derechos humanos no puede dejar de lado el dinamismo exigente de las mayorías populares, pues históricamente ha sido ese dinamismo - llámese lucha de clases o llámese conflicto de intereses - lo que ha ido llevando a ciertos avances sociales. La legalización de las organizaciones campesinas no tiene, por lo tanto, la finalidad de domesticarlas y ponerlas al servicio del sistema y no puede, por consiguiente, rebajar el nivel de

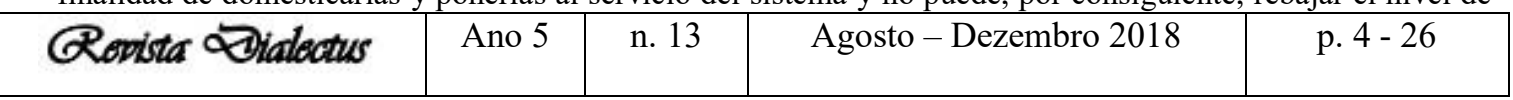




\section{CONCLUSIÓN}

La FL construye una compresión compleja de derechos humanos, que busca no mutilar lo humano, pues parte del sujeto vivo y necesitado como su punto crítico. Evita y se opone al solipsismo normativo y al formalismo, para abordar derechos humanos desde las diversas parcelas de la realidad histórica donde inciden. Al dar la razón de la complejidad de derechos humanos, se les entiendecomo un conjunto de prácticas sociales, simbólicas, culturales, jurídicas, económicas e institucionales de la "comunidad de víctimas", que les permite constituirse en sujeto yreaccionar contra los excesos de cualquier tipo de poder, modificando las tramas sociales para lograr acceder a los bienes para las satisfacción de las necesidades de producción y reproducción de vida, es un punto de partida adecuado para una compresión compleja de derechos humanos.

La crítica del uso ideologizado de derechos humanos es desarrollada por la FL desde diversas perspectivas. Una es la superación del logos abstracto por medio de un logos histórico, concretado en el método de la historización de los conceptos, como propone Ellacuría. Éste busca la verificación histórica para mostrar si es verdad y en qué sentido lo es, cualquier principio, formulación o discurso abstracto. En efecto, la necesidad de historizar los derechos humanos surge de su complejidad, ya que no pocas veces son utilizados ideológicamente no al servicio de la producción, reproducción y desarrollo de vida, sino a los intereses de ciertos grupos de poder que al totalizar la manera en que ellos producen y acceden a los bienes para la satisfacción de necesidades, niegan este acceso al otro. Una crítica que señala que los derechos humanos se transforman en una agresividad humanitaria: violar los derechos humanos de aquellos que los violan. La FL realiza una crítica de la Modernidad, y busca que derechos humanos se inserte, en palabras de Ellacuría, en "una civilización de la pobreza".

\section{REFERENCIAS}

lucha y de exigencia reivindicativa, sino que debe encauzar esa tremenda fuerza para que en su lucha contra la violencia institucional se siga más bienes que males. La legalización puede traer el peligro de desvirtuar y burocratizar su ímpetu, como nos lo enseña la historia del sindicalismo salvadoreño, pero les daría cierta protección legal y cierto margen de maniobra" (Ellacuría, 1993c, p. 664 [negrillas mías]).

\begin{tabular}{|c|c|c|c|c|}
\hline Revita Alatectus & Ano 5 & n. 13 & Agosto - Dezembro 2018 & p. $4-26$ \\
\hline
\end{tabular}


BIEL, Robert.EI nuevo imperialismo. Crisis y contradicciones en las relaciones Norte-Sur. México: Siglo XXI, 2007.

BOFF, Leonardo. Ética da Vida. Rio de Janeiro: Sextante, 2005.

DUSSEL, Enrique. Estado de guerra permanente y razón cínica: John Locke. In: Materiales para una política de la liberación. México: UANL-Plaza y Valdés Editores, 2007.

DUSSEL, Enrique. Filosofía de la liberación. Bogotá: Nueva América, 1996.

ELLACURÍA, Ignacio, "El desafío cristiano de la teología de la liberación” In: Escritos Teológicos. Tomo I. San Salvador: UCA Editores, 2000c.

ELLACURÍA, Ignacio, "En torno al concepto y a la idea de liberación", In: Escritos Teológicos. Tomo I. San Salvador: UCA Editores, $2000 \mathrm{~b}$.

ELLACURÍA, Ignacio. Comentarios a la Carta Pastoral. In: Veinte años de historia en El Salvador (1969-1989). Escritos políticos. Tomo II. San Salvador: UCA Editores, 1993d.

ELLACURÍA, Ignacio. El desafío de las mayorías pobres. In: Revista de Estudios Centroamericanos (ECA), 493-494, San Salvador, 1989.

ELLACURÍA, Ignacio. El papel de las organizaciones populares en la actual situación del país. In: Veinte años de historia en El Salvador (1969-1989). Escritos políticos. Tomo II. San Salvador: UCA Editores, 1993e.

ELLACURÍA, Ignacio. El testamento de Sartre. In: Escritos Filosóficos. Tomo III. San Salvador: UCA Editores, 2001a.

ELLACURÍA, Ignacio. En torno al concepto y a la idea de liberación.In: Escritos Teológicos. Tomo I. San Salvador: UCA Editores, 2000d.

ELLACURÍA, Ignacio. Filosofía de la realidad histórica. San Salvador: UCA Editores, 1999a.

ELLACURÍA, Ignacio. Función liberadora de la filosofía. In: Veinte años de historia en El Salvador (1969-1989). Escritos políticos. Tomo I. San Salvador: UCA Editores, 1993b.

ELLACURÍA, Ignacio. Historización del bien común y de los derechos humanos en una sociedad dividida. In: Escritos Filosóficos. Tomo III. San Salvador: UCA Editores, $2001 b$.

ELLACURÍA, Ignacio. La construcción para un futuro distinto para la humanidad. In: Escritos Teológicos. Tomo I. San Salvador: UCA Editores, 2000a.

ELLACURÍA, Ignacio. La construcción para un futuro distinto para la humanidad. In: Escritos Teológicos. Tomo I. San Salvador: UCA Editores, 2000e.

\begin{tabular}{|c|c|c|c|c|}
\hline Qovista Dialectus & Ano 5 & n. 13 & Agosto - Dezembro 2018 & p. $4-26$ \\
\hline
\end{tabular}


ELLACURÍA, Ignacio. La Iglesia y las organizaciones populares en El Salvador. In: Veinte años de historia en El Salvador (1969-1989). Escritos políticos. Tomo II. San Salvador: UCA Editores, 1993c.

ELLACURÍA, Ignacio. Universidad, derechos humanos y mayorías populares. In: Escritos Universitarios. San Salvador:UCA Editores, 1999b.

ELLACURÍA, Ignacio. Utopía y profetismo. In: MysteriumLiberationis. Conceptos fundamentales de la teología de la liberación. Tomo I. San Salvador: UCA Editores, $1993^{\mathrm{a}}$.

FARIÑAS DULCE, María José. Los derechos humanos: desde la perspectiva sociológicajurídica a la "actitud postmoderna". Madrid: Instituto Bartolomé de las Casas/Dikinson, 2006.

GONZÁLEZ, Antonio. Orden mundial y liberación. In: Revista de Estudios Centroamericanos (ECA), no. 549, 1994, pp. 629-652.

GONZÁLEZ, Antonio. Prólogo. In: SENENT, Juan Antonio, Ellacuría y los derechos humanos. Bilbao: Desclée de Brouwer, 1998.

HERRERA FLORES, Joaquín, Los derechos humanos como productos culturales. Crítica del humanismo abstracto. Madrid: Catarata, 2005.

HINKELAMMERT, Franz. Solidaridad o suicidio colectivo. Heredia: Ambientico Ediciones, 2003.

NICOLAU-COLL, Agusti. Derechos humanos y diversidad cultural. In:Ixtus57, Cuernavaca, 2006.

NOLAN, Albert. Jesús, hoy. Una espiritualidad de libertad radical. Santander: Sal Terrae, 2007.

PANIKKAR, Raimon. La notion des droits de l'homme, est-elle un concept occidental? In: Diogène 129, 1982.

QUIJANO, Aníbal. Colonialidad del poder y clasificación social. In: Journal of WorldSystems Research, VI, 2, summer/fall 2000, Special issue: Festchrift for Immanuel Wallerstein - Part I.

ROSILLO, Alejandro et al. Introdução ao pensamento jurídico crítico desde a filosofia da libertação. Curitiva:D'Placido, 2018.

ROSILLO, Alejandro. Fundamentação dos direitos humanos desde a Filosofia da libertação. Ijuí: Editora Unijuí, 2015.

ROSILLO, Alejandro. La historización de los derechos humanos. Un aporte de Ignacio Ellacuría al pensamiento jurídico. In: ROSILLO, Alejandro et al. (Coord.). Derecho, justicia y derechos humanos. Filosofía y experiencias históricas. San Luis Potosí: Universidad Autónoma de San Luis Potosí, 2004.

\begin{tabular}{|l|l|l|l|l|}
\hline Qevista Dialectus & Ano 5 & n. 13 & Agosto - Dezembro 2018 & p. 4-26 \\
\hline
\end{tabular}


ROSILLO, Alejandro. La inversión ideológica de los derechos humanos en el pensamiento de Franz Hinkelammert. In: LEAL, Jackson da Silva et al. (coord.). Direitos humanos na América Latina. Curitiba: Multideia, 2016.

ROSILLO, Alejandro. La tradición hispanoamericana de derechos humanos. La defensa de los pueblos indígenas en la obra y la praxis de Bartolomé de Las Casas, Alonso de la Veracruz y Vasco de Quiroga. Quito: Corte Constitucional del Ecuador, 2012.

SANTOS, Boaventura de Sousa. Sociología jurídica crítica. Para un nuevo sentido común en el derecho. Madrid: Trotta, 2009.

SHIVA, Vandana. Derecho a la alimentación, libre comercio y fascismo. In:La globalización de los derechos humanos. Barcelona: Crítica, 2006.

SOBRINO, Jon. Fuera de los pobres no hay salvación. Pequeños ensayos utópicoproféticos. Madrid: Trotta, 2007.

SOBRINO, Jon. Fuera de los pobres no hay salvación. Pequeños ensayos utópicoproféticos, Madrid: Trotta, 2007.

TAMAYO-ACOSTA, Juan José. El método de historización de los conceptos teológicos en Ellacuría. In: NICOLÁS, Juan Antonio et al. (Ed.). Historia, ética y ciencia. El impulso crítico de la filosofía de Zubiri. Granda: Comares, 2007.

WALLERSTEIN, Immanuel. Universalismo europeo. El discurso del poder. México: Siglo XXI, 2007.

ZYGMUNT, Bauman. Vidas desperdiciadas. La modernidad y sus parias. Barcelona: Paidós, 2005. 